\title{
Methane and hydrogen sensing properties of catalytic combustion type single-chip micro gas sensors with two different Pt film thicknesses for heaters
}

\author{
Woongjin Jang ${ }^{1,2}$, Joon-Shik Park ${ }^{1 *}$, Ki-Won Lee ${ }^{3}$ and Yonghan Roh ${ }^{2}$
}

\begin{abstract}
A catalytic combustible type single-chip micro gas sensor was fabricated by MEMS technology and responses with input powers and methane and hydrogen gas concentrations were characterized. The ranges of responses at Pt thickness of $450 \mathrm{~nm}$ and input power of $128 \mathrm{~mW}$ were 1.076-2.433 $\mathrm{mV}$ for methane concentrations of 2315-5787 ppm, and $0.965-2.514 \mathrm{mV}$ for hydrogen concentrations of 282-706 ppm, respectively. The ranges of responses at Pt thickness of $150 \mathrm{~nm}$ and input power of $112 \mathrm{~mW}$ were $0.192-0.438 \mathrm{mV}$ for methane concentrations of 2315-5787 ppm and $0.949 \mathrm{mV}$ to $2.496 \mathrm{ppm}$ for hydrogen concentrations of 282-706 ppm, respectively. The responses to $\mathrm{H}_{2}$ concentration ratios were $3.65 \mathrm{mV} / 10^{3} \mathrm{ppm}$ for a micro gas sensor with a $450 \mathrm{~nm}$ thick heater and $3.81 \mathrm{mV} / 10^{3} \mathrm{ppm}$ for a micro gas sensor with a $150 \mathrm{~nm}$ thick heater. But in the case of methane gas response, the response to concentration ratios of the micro gas sensor using the $150 \mathrm{~nm}$ thick Pt heater was remarkably different from the case of the $450 \mathrm{~nm}$ thick Pt heater. The ratios for $\mathrm{CH}_{4}$ were $3.51 \mathrm{mV} / 10^{4} \mathrm{ppm}$ for the micro gas sensor with a $450 \mathrm{~nm}$ thick heater and $0.6 \mathrm{mV} / 10^{4} \mathrm{ppm}$ for the micro gas sensor with a $150 \mathrm{~nm}$ thick heater, respectively. From these results, the micro gas sensor that has the thicker heater with a thickness of $450 \mathrm{~nm}$ showed higher sensitivity to methane gas than the micro gas sensor with a thinner heater with a thickness of $150 \mathrm{~nm}$.
\end{abstract}

Keywords: Single-chip, Catalytic, Combustible, Micro gas sensor, Methane and hydrogen gases, Pt heater

\section{Background}

It is expected that the production of natural gas will inevitably increase for a while until the switch to sustainable and eco-friendly energy sources. Natural gas, a "bridge fuel," is known to have environmental credentials but the benefits are marred by leaks from human activities and natural sources [1-4]. A micro-scale gas sensor will likely be able to quantitatively measure leaks with low power consumption and speediness. And along with quantity, another topic for the micro gas sensor, is recognizing the type of gas. The response of a micro gas sensor might be suitable for a location but it is usually hard to recognize

\footnotetext{
*Correspondence: jspark@keti.re.kr

${ }^{1}$ Smart Sensor Research Center, Korea Electronics Technology Institute,

Seongnam-si, Gyeonggi-do 13509, Republic of Korea

Full list of author information is available at the end of the article
}

what type of gas it is. The main component of natural gas, methane, is sometimes blended with hydrogen, and there is commercial interest due to the effectiveness and low emissions of $\mathrm{NO}_{x}$ [5]. However, the gas sensing of microchips have limits of selectivity and stability to exceed the current level $[6,7]$. A variety of ways of enhancing gas selectivity have been tried. The $\mathrm{Cu}$-BTC metal-organic framework was used as a sensing layer and measured work function [8]. In the field of semiconducting types, working temperature-modulating frequencies, grain size of the sensing layer film, filter use, and the facet properties of the surface of sensing materials have shown potential as methods to obtain selectivity [9-11]. Besides chemical approaches, the refractive index changes of the sensing layers [12] and the resonance frequency of the sensor for gas type [13] have been investigated. The combustible type gas sensor is a transducer that converts the 
heat of a combustion reaction into an electric signal. The reactivity leads to a response that varies with different gases in the equal condition of intensive property, and a catalytic combustible type gas sensor could be able to harness this variety to discriminate chemicals.

In this work, the micro gas sensor platforms embedding thin film micro-heaters with a meander structure were realized by the MEMS process. The film heater has less power consumption than the coil of the traditional pellistor type by between one order and two orders of magnitude [6]. The catalytic combustible type micro gas sensors were measured and how to discriminate between hydrogen and methane gas was studied.

\section{Methods}

\section{Design and fabrication}

A sensing device and compensation device were integrated into the single-chip micro gas sensor. Each of the thin film layers of the micro gas sensor was fabricated under same conditions as in previous work [14] except for the design and thickness of the heaters. Here, we briefly describe the fabrication process as follows. Using low pressure chemical vapor deposition (LPCVD), $2 \mu \mathrm{m}$ thick $\mathrm{SiN}_{\mathrm{x}}$ film was deposited on a $500 \mu \mathrm{m}$ thick, 4-inch double-sided polished p-type $\mathrm{Si}(100)$ wafer. And $10 \mathrm{~nm}$ $\mathrm{Ta} / 150 \mathrm{~nm}$ Pt film was deposited as a micro heater, and patterned using the reactive ion etching (RIE) process on the front side of the wafer. Using the plasma-enhanced chemical vapor deposition (PECVD) method, a $\mathrm{SiO}_{\mathrm{x}} /$ $\mathrm{SiN}_{\mathrm{x}} / \mathrm{SiO}_{\mathrm{x}}$ layer was deposited as an insulator layer, and then patterned for the formation of an electrode pad using the RIE process. The backside of bulk silicon was anisotropically etched to form membranes in $\mathrm{KOH}$ solution after patterning the SiNx film using the RIE process. The thicknesses of the heater that were deposited were $150 \mathrm{~nm}$ and $450 \mathrm{~nm}$ due to a trade-off between power consumption and response or output voltage. The micro platform for the single-chip micro gas sensor, which consists of a sensing device and compensation device, was fabricated with a size of $5.9 \mathrm{~mm} \times 3.9 \mathrm{~mm}$. The sensing device and the compensation device were connected in a series and the electrodes of the micro gas sensors were one output and two input. In order to have same resistance, the micro patterns of both devices were defined with symmetry. Shinwoo Electronics Co., Ltd. provided the sensing materials to use for the micro gas sensors. The fabricated micro platforms were mounted on TO- 8 using epoxy and the electrode pads were bonded to packages with gold wires. The average resistance for the $450 \mathrm{~nm}$ thick heaters was $41.2 \Omega$ and the average for the $150 \mathrm{~nm}$ thick heaters was $292.3 \Omega$. After applying sensing materials paste to the heater of the sensing device, the paste was dried to evaporate the organic solvent at
$200{ }^{\circ} \mathrm{C}$ for $15 \mathrm{~min}$. The structure of the micro platform and image of the micro gas sensor can be seen in Fig. 1.

\section{Temperature characteristics of the micro heaters using two different $\mathrm{Pt}$ film thicknesses}

The temperatures of the Pt heaters with electric input power were measured with an IR camera (MobIR M8, Wuhan Guide Infrared Co., Ltd.). The emissivity of the object was set for 0.2 [15]. The measurement was carried out for one heater of the two heaters in single chip before the application of the catalyst materials, and the results are shown in Fig. 2.

\section{Gas sensing measurement}

The gas sensing performances of the fabricated micro gas sensors were studied with the following steps. The micro gas sensor package was connected to the socket of a 1728 cc static acrylic container. The socket was connected to a Wheatstone bridge circuit outside the container by cable. As for gases for the test, $10 \%$ methane was balanced with argon and $1.22 \%$ hydrogen was balanced with nitrogen. After electric power was supplied, in operation mode, the output voltage was regulated to nearly $0 \mathrm{~V}$ and a certain amount of gas extracted from the cylinder was injected into the container. It was assumed that the injected gases were most immediately diffused throughout the container, and uniform concentrations were made. The micro gas sensor responded to the gas and the output voltage was reached within $25 \mathrm{~s}$ in all cases. After $1 \mathrm{~min}$, the mixed gas of air and test gas was released outside by a rotary pump connected to the container. Fresh air was replaced through an inlet at the same time, and then the output voltage recovered to the initial value. When the signal levelled off, the measuring steps were repeated. The output voltage values were automatically recorded every $5 \mathrm{~s}$ using a multi-meter (Model: Fluke 287) and PC.

\section{Results and discussion}

The ranges of responses or output voltages of micro gas sensors with a $450 \mathrm{~nm}$ thick heater were from 1.076 to $2.433 \mathrm{mV}$ for methane concentrations from 2315 to $5787 \mathrm{ppm}$ (Fig. 3a), and 0.965-2.514 mV for hydrogen concentrations of 282-706 ppm (Fig. 3b). The micro gas sensors with $150 \mathrm{~nm}$ thick heaters, the responses were $0.192-0.438 \mathrm{mV}$ for methane concentrations of 2315$5787 \mathrm{ppm}$ (Fig. 3c) and 0.949-2.496 ppm for hydrogen concentrations of 282-706 ppm (Fig. 3d). The micro gas sensor with two $450 \mathrm{~nm}$ thick heaters consumed power of $128 \mathrm{~mW}$ and the micro gas sensor with two $150 \mathrm{~nm}$ thick heaters consumed $112 \mathrm{~mW}$, respectively. The input powers with Pt heater thicknesses and responses or output 


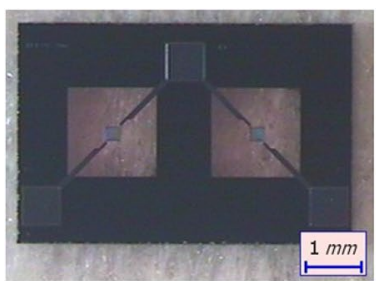

a

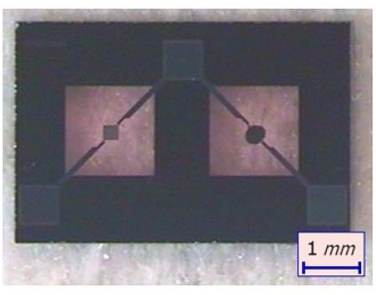

c

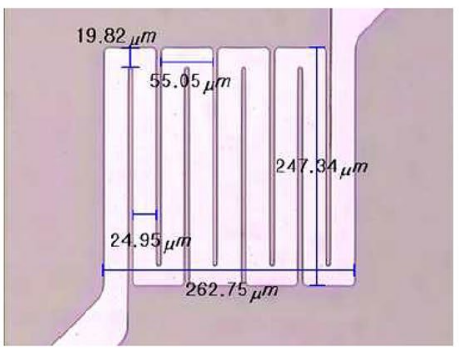

f

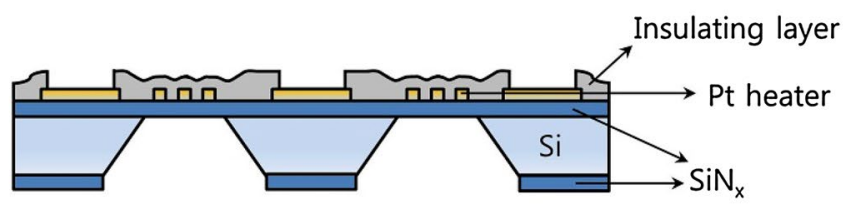

b

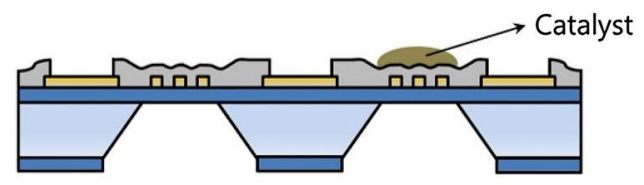

d

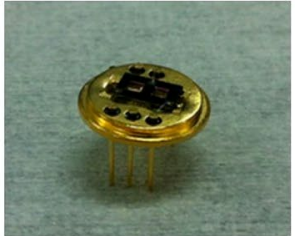

e

Fig. 1 Images of the catalytic combustible type single-chip micro gas sensor platforms: top view of fabricated micro gas sensor platforms without catalyst materials (a) and with catalyst materials only on the right-hand side membrane (c). b, $\mathbf{d}$ Schematic views of the cross-section structures of $\mathbf{a}$ and $\mathbf{c}$. e Image of single-chip micro gas sensor platform c packaged on TO-8. f Top image of fabricated Pt micro heater in single-chip micro gas sensor platform

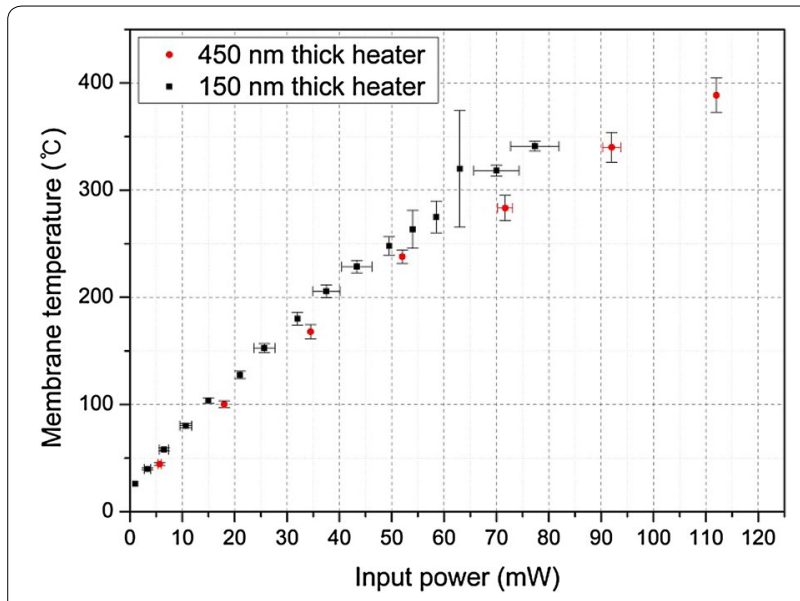

Fig. 2 Graph of input power vs. membrane temperature for one of two heaters in single chip. Two chips were fabricated with $150 \mathrm{~nm}$ (square) and $450 \mathrm{~nm}$ (circle) thick Pt films for heaters, respectively. So, he total power of two heaters in a single chip is two times the input power indicated in the graph voltages of catalytic combustible type single-chip micro gas sensors are summarized in Table 1.

The two kinds of Pt thin film micro heaters were designed with the same pattern and two different $\mathrm{Pt}$ thicknesses of $150 \mathrm{~nm}$ and $450 \mathrm{~nm}$. The electrical input power of the micro gas sensor with a $450 \mathrm{~nm}$ thick $\mathrm{Pt}$ heater was $128 \mathrm{~mW}$, and the electrical input power of the micro gas sensor with a $150 \mathrm{~nm}$ thick Pt heater was $112 \mathrm{~mW}$. Even though the concentration ranges were different between hydrogen gas in the several hundreds and methane gas in the several thousands, in the case of hydrogen gas response, the response to concentration ratios of the micro gas sensor using a $150 \mathrm{~nm}$ thick Pt heater was quite similar to the case of $450 \mathrm{~nm}$ thick. The response to $\mathrm{H}_{2}$ concentration ratios were $3.65 \mathrm{mV} / 103 \mathrm{ppm}$ for the micro gas sensor with a $450 \mathrm{~nm}$ thick heater and $3.81 \mathrm{mV} / 10^{3} \mathrm{ppm}$ for the micro gas sensor with a $150 \mathrm{~nm}$ thick heater, as shown in Fig. 4. But, in the case of methane gas 


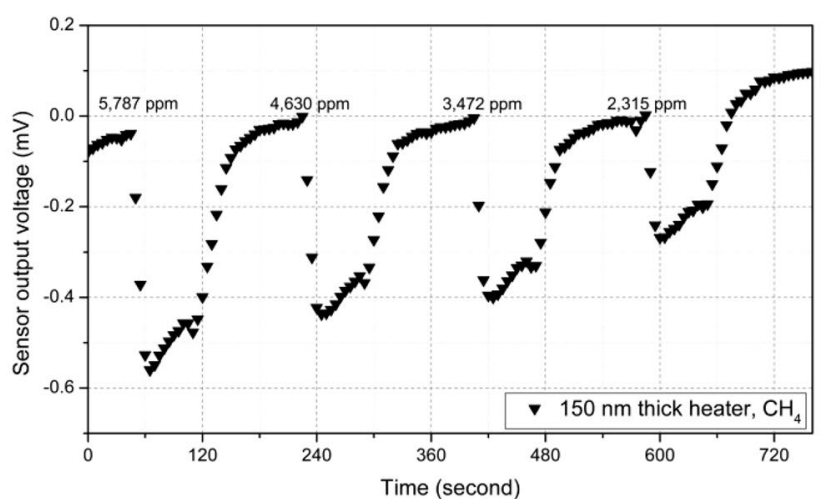

$\mathbf{a}$

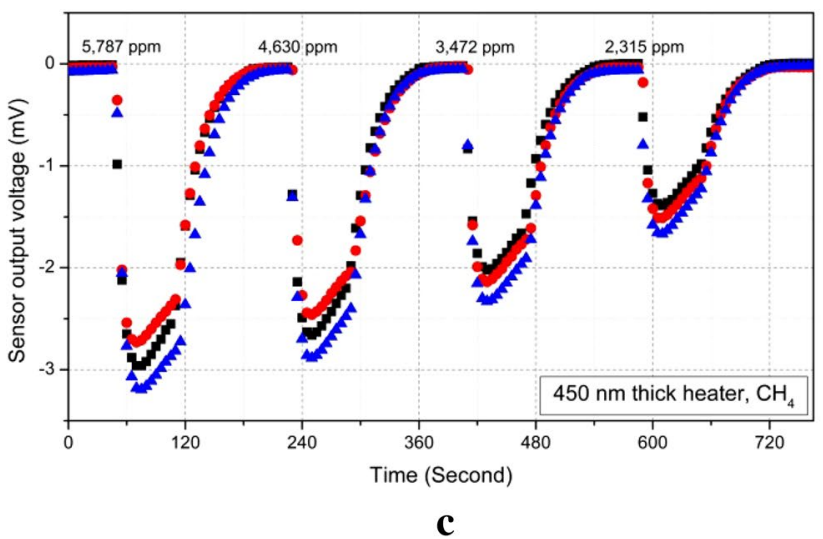

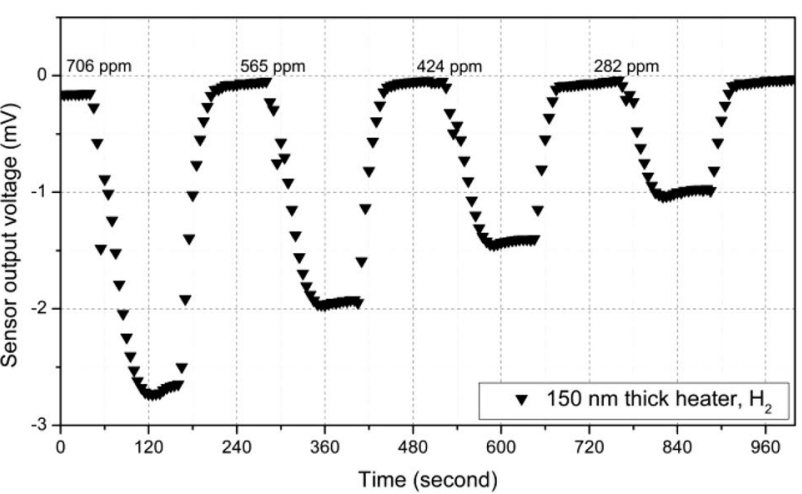

b

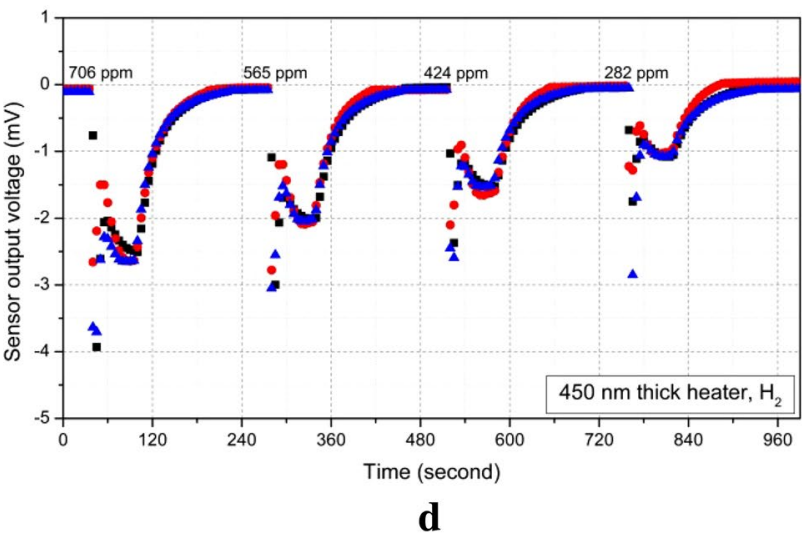

d

Fig. 3 Gas response properties of catalytic combustible type single-chip micro gas sensors to varying concentrations of $\mathrm{CH}_{4}$ and $\mathrm{H}_{2}$ gases: $\mathbf{a}$, $\mathbf{b}$ one micro gas sensor with $150 \mathrm{~nm}$ thick heater, $\mathbf{c}$, $\mathbf{d}$ three micro gas sensors with $450 \mathrm{~nm}$ thick heaters

Table 1 Responses to methane and hydrogen gas concentrations of fabricated catalytic combustible type single-chip micro gas sensors with two different Pt heater thicknesses and input powers

\begin{tabular}{|c|c|c|c|c|c|}
\hline \multicolumn{2}{|l|}{ Input } & \multicolumn{4}{|c|}{ Output } \\
\hline \multirow{2}{*}{$\begin{array}{l}\text { Pt heater } \\
\text { thickness } \\
(\mathrm{nm})\end{array}$} & \multirow{2}{*}{$\begin{array}{l}\text { Input } \\
\text { power } \\
(\mathrm{mW})\end{array}$} & \multicolumn{2}{|c|}{$\begin{array}{l}\mathrm{CH}_{4} \text { concentration } \\
\text { response }\end{array}$} & \multicolumn{2}{|c|}{$\begin{array}{l}\mathrm{H}_{2} \text { concentration } \\
\text { response }\end{array}$} \\
\hline & & ppm & $\mathrm{mV}$ & ppm & $\mathrm{mV}$ \\
\hline \multirow[t]{4}{*}{150} & 112 & 2315 & 0.192 & 282 & 0.949 \\
\hline & & 3472 & 0.326 & 424 & 1.350 \\
\hline & & 4630 & 0.367 & 565 & 1.900 \\
\hline & & 5787 & 0.438 & 706 & 2.496 \\
\hline \multirow[t]{4}{*}{450} & 128 & 2315 & 1.076 & 282 & 0.965 \\
\hline & & 3472 & 1.719 & 424 & 1.480 \\
\hline & & 4630 & 2.164 & 565 & 1.959 \\
\hline & & 5787 & 2.433 & 706 & 2.514 \\
\hline
\end{tabular}

response, the response to concentration ratios of the micro gas sensor using a $150 \mathrm{~nm}$ thick Pt heater was remarkably different from the case of the $450 \mathrm{~nm}$ thick
Pt heater. The ratios for $\mathrm{CH}_{4}$ were $3.51 \mathrm{mV} / 10^{4} \mathrm{ppm}$ for the micro gas sensor with a $450 \mathrm{~nm}$ thick heater and $0.6 \mathrm{mV} / 10^{4} \mathrm{ppm}$ for the micro gas sensor with a $150 \mathrm{~nm}$ thick heater, as shown in Fig. 4. The responses to the concentration ratios above were obtained through the linear fitting of graphs in Fig. 4 using Origin software from OriginLab ${ }^{\circledR}$. From these results, the micro gas sensor that had the thicker heater with a thickness of $450 \mathrm{~nm}$ showed higher sensitivity to methane gas than the micro gas sensor with the thinner heater with a thickness of $150 \mathrm{~nm}$. It is thought that the $150 \mathrm{~nm}$ thick heater at $112 \mathrm{~mW}$ provided sufficient energy for hydrogen gas sensing. But, in the case of methane gas sensing, not the $150 \mathrm{~nm}$ thick heater but $450 \mathrm{~nm}$ thick heaters were required to detect methane gas. Because the thicker Pt heater has a relatively higher temperature coefficient of resistance [16] than the thinner Pt heater, the thicker Pt heater could supply much heat energy to combust methane gas with higher activation energy than the case of hydrogen gas. However, the micro gas sensor with the thinner $\mathrm{Pt}$ heater has an economic advantage for hydrogen gas sensing in this work. 


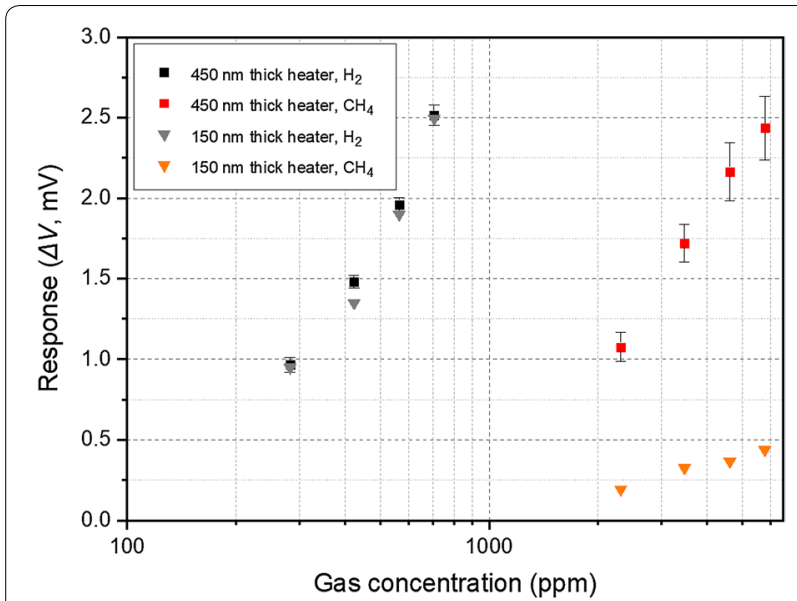

Fig. 4 Response vs. gas concentration of the fabricated catalytic combustible type single-chip micro gas sensors

\section{Conclusions}

Catalytic combustible type single-chip micro gas sensors were designed and fabricated with two different heater thicknesses of $150 \mathrm{~nm}$ and $450 \mathrm{~nm}$, and responses to methane and hydrogen gases were measured. The responses to $\mathrm{H}_{2}$ concentration ratios were quite similar, such as $3.65 \mathrm{mV} / 103 \mathrm{ppm}$ for the micro gas sensor with a $450 \mathrm{~nm}$ thick heater and $3.81 \mathrm{mV} / 10^{3} \mathrm{ppm}$ for the micro gas sensor with a $150 \mathrm{~nm}$ thick heater. Meanwhile, the responses to $\mathrm{CH}_{4}$ concentration ratios were remarkably different between $3.51 \mathrm{mV} / 10^{4} \mathrm{ppm}$ for micro gas sensors with $450 \mathrm{~nm}$ thick heaters and $0.6 \mathrm{mV} / 10^{4} \mathrm{ppm}$ for the micro gas sensor with the $150 \mathrm{~nm}$ thick heater, respectively. From these results, it was seen that the micro gas sensor with the thicker heater with a thickness of $450 \mathrm{~nm}$ showed higher sensitivity to methane gas than the micro gas sensor with a thinner heater with a thickness of $150 \mathrm{~nm}$. The catalytic combustible type single-chip micro gas sensor that was developed could be used for the leakage detection of methane and hydrogen gases after a long-term reliability test.

\section{Authors' contributions}

WJ and JSP made substantial contributions to conception, fabrication, acquisition of data, and analysis. WJ and JSP were involved in drafting the manuscript and revising it critically for important intellectual content. KWL and YR gave approval for the version. All authors read and approved the final manuscript.

\section{Author details}

1 Smart Sensor Research Center, Korea Electronics Technology Institute, Seongnam-si, Gyeonggi-do 13509, Republic of Korea. ${ }^{2}$ Department of Electronic and Electrical Engineering, Sungkyunkwan University, Suwon-si, Gyeonggi-do 16419, Republic of Korea. ${ }^{3}$ Shinwoo Electronics Co., Ltd, Hwaseong-si, Gyeonggi-do 18529, Republic of Korea.

\section{Competing interests}

The authors declare that they have no competing interests.

\section{Funding}

This work was supported by Project No. SD122962 of the SMBA and project No. N0001711 of an international collaboration program by the KIAT and MOTIE in Korea. And J-S Park was partially supported by project CAP-13-1-KITECH of the Ministry of Science, ICT and NST. We thank the government for research funding.

\section{Publisher's Note}

Springer Nature remains neutral with regard to jurisdictional claims in published maps and institutional affiliations.

Received: 12 September 2018 Accepted: 8 November 2018

Published online: 15 November 2018

\section{References}

1. Brandt AR, Heath GA, Kort EA, O'Sullivan F, Pétron G, Jordaan SM, Tans P, Wilcox J, Gopstein AM, Arent D, Wofsy S, Brown NJ, Bradley R, Stucky GD, Eardley D, Harriss R (2014) Methane leaks from North American natural gas systems. Science 343:733-735

2. Tollefson J (2013) Methane leaks erode green credentials of natural gas. Nature 493:12

3. Phillips NG, Ackley R, Crosson ER, Down A, Hutyra LR, Brondfield M, Karr JD, Zhao K, Jackon RB (2013) Mapping urban pipeline leaks: methane leaks across Boston. Environ Pollut 173:1-4

4. Nisbet EG, Dlugokencky EJ, Bousquet P (2014) Methane on the rise-again. Science 343:493-495

5. Diéguez PM, Urroz JC, Marcelino-Sádaba S, Pérez-Ezcurdia A, Benito-Amurrio M, Sáinz D, Gandía LM (2014) Experimental study of the performance and emission characteristics of an adapted commercial four-cylinder spark ignition engine running on hydrogen-methane mixtures. Appl Energy 113:1068-1076

6. Hübert T, Boon-Brett L, Black G, Banach U (2011) Hydrogen sensors-a review. Sens Actuators B Chem 157:329-352

7. Lakkis S, Younes R, Alayli Y, Sawan M (2014) Review of recent trends in gas sensing technologies and their miniaturization potential. Sens Rev 34:24-35

8. Davydovskaya P, Pohle R, Tawil A, Fleischer M (2013) Work function based gas sensing with Cu-BTC metal-organic framework for selective aldehyde detection. Sens Actuators B Chem 187:142-146

9. Vergara A, Llobet E, Brezmes J, Ivanov P, Cané C, Gràcia I, Vilanova X, Correig X (2007) Quantitative gas mixture analysis using temperature-modulated micro-hotplate gas sensors: selection and validation of the optimal modulating frequencies. Sens Actuators B Chem 123:1002-1016

10. Angelis LD, Riva R (1995) Selectivity and stability of a tin dioxide sensor for methane. Sens Actuators B Chem 28:25-29

11. Zhang L, Zhao J, Lu H, Gong L, Li L, Zheng J, Li H, Zhu Z (2011) High sensitive and selective formaldehyde sensors based on nanoparticle-assembled ZnO micro-octahedrons synthesized by homogeneous precipitation method. Sens Actuators B Chem 160:364-370

12. Reddy K, Guo Y, Liu J, Lee W, Oo MKK, Fan X (2011) On-chip Fabry-Pérot interferometric sensors for micro-gas chromatography detection. Sens Actuators B Chem 159:60-65

13. Sanz DA, Unigarro EA, Osma JF, Segura-Quijano F (2013) Low cost wireless passive microsensors for the detection of hazardous compounds in water systems for control and monitoring. Sens Actuators B Chem 178:26-33

14. Jang W, Kim I, Jeong Y, Park K, Park S, Yoon M, Roh Y, Park J (2013) Characteristics of fabricated catalytic combustible micro gas sensor with low power consumption for detecting methane leakage of compressed natural gas bus. J Electroceram 31:280-285

15. Mailly F, Giani A, Bonnot R, Temple-Boyer P, Pascal-Delannoy F, Foucaran A, Boyer A (2001) Anemometer with hot platinum thin film. Sens Actuators A Phys 94:32-38

16. Zhang J, Nagao Y, Kuwano S, Ito Y (1997) Microstructure and temperature coefficient of resistance of platinum films. Jpn J Appl Phys 36:834-839 